\title{
An overview of compensated work-related injuries among Korean firefighters from 2010 to 2015
}

\author{
Hyung Doo Kim², Yon Soo $\mathrm{An}^{3}$, Dong Hyun $\mathrm{Kim}^{4}$, Kyung Sook Jeong ${ }^{5}$ and Yeon Soon $\mathrm{Ahn}^{1 *}$
}

\begin{abstract}
Background: Although one in two firefighters in South Korea have experienced work-related injuries, there are few studies which show the overview description on work-related injuries and its analysis regarding such causes. Therefore, we aimed to show the overview of compensated work-related injuries in order to serve fundamental data for establishing prevention policies on work-related injuries for Korean firefighters.

Methods: We requested the all claimed work-related injury data of Korean firefighters from 2010 to 2015 to the Korean National Fire Agency (NFA). The data from NFA including 2457 claimed cases was analyzed and we confirmed, 2154 approved work-related injuries for the kinds of job activities, cause of accident and type of injuries. Among 2154 approved cases, we analyzed more variables for the sex, age, and job duration of 1344 compensated cases through served text file on summary of accident.

Results: The Government Employees Pension Service (GEPS) recognized 2154 (87.7\%) approved work-related injuries among 2457 claimed cases. The incidence of work-related injuries per 1000 firefighters was 9.8 persons. By region, the incidence of work-related injuries per 1000 firefighters ranged from a maximum of 14.5 to a minimum of 4.0. The most common job activity caused the accident was fire suppression (18.0\%), followed by Emergency medical services (EMS) (17.5\%) and training (10.7\%). The most common cause of these accident was movement imbalance (30.3\%), followed by falls (18.9\%) and traffic accident (13.4\%). In these work-related injuries, sprains and bruises were the most common type of injury (27.2\%), and the most commonly injured body site was the upper and lower back (25.3\%). Data from identified 1344 firefighters showed that 1264 (94.0\%) were male and 80 (6.0\%) were female. Age group was the highest in the 40s with 623 cases (46.4\%), and job duration was the highest with 650 cases in $5-10$ years $(48.4 \%)$.
\end{abstract}

Conclusion: In this study, we could obtain the preliminary data necessary to establish preventive measures, including the cause of accident and region with high accident rates. However, the number of applications for compensated injuries was very small compared to the frequency of injuries found in previous studies. The lack of appropriate treatment suggested that many firefighter injuries can become chronic. In this study, we suggest that it is necessary to introduce an injury monitoring system and improve the accessibility of compensated injuries.

Trial registration: CR318031. Registered 20 June 2018.

Keywords: Firefighter, Korean, Occupational injury, Occupational accident, Occupational environment, Work-related injury, Industrial accident

\footnotetext{
* Correspondence: ysahn1203@gmail.com

${ }^{1}$ Department of Preventive Medicine and Institute of Occupational and

Environmental Medicine, Wonju College of Medicine, Yonsei University, 20

Ilsan-ro, Wonju, Gangwon-do 26426, Republic of Korea

Full list of author information is available at the end of the article
}

(c) The Author(s). 2018 Open Access This article is distributed under the terms of the Creative Commons Attribution 4.0 International License (http://creativecommons.org/licenses/by/4.0/), which permits unrestricted use, distribution, and reproduction in any medium, provided you give appropriate credit to the original author(s) and the source, provide a link to the Creative Commons license, and indicate if changes were made. The Creative Commons Public Domain Dedication waiver (http://creativecommons.org/publicdomain/zero/1.0/) applies to the data made available in this article, unless otherwise stated. 


\section{Background}

The incidence of work-related injuries among firefighters in South Korea is devastating, as highlighted in a study of Korean firefighters that surveyed via mail. According to the survey, $1216(12.0 \%)$ of 10,127 fire suppression workers, $586(18.5 \%)$ of 3169 EMS workers, and 299 (17.8\%) of 1681 officers, had experienced one or more workplace injuries during the previous 12 months [1]. The risk of non-fatal injuries in firefighters was 1.4-7.4 times higher than that of other occupations in United States [2]. Although the occupational risk to firefighters is higher than normal population, the rate of on-duty deaths per 100,000 firefighters in South Korea is 2 times higher than that of United States (33 Korean firefighters died on duty from 2010 to 2014), suggesting that they are exposed to considerable occupational risk [3].

According to the Industrial Accident Analysis Data from 2010 to 2014 released by the Korea Occupational Safety \& Health Agency, the average incidence of all industrial accidents per 1000 persons in South Korea is 6.0. The incidence of work-related injuries per 1000 firefighters is 1.6 times the average incidence of all industrial accidents per 1000 persons in South Korea. In addition, firefighters have a higher incidence of musculoskeletal diseases and noise-induced hearing loss due to the nature of the work, which exposed to various harmful factors than other occupations [4-8]. Although there is growing interest in work-related injuries among firefighters, there are only few studies that provide an overview of injuries to firefighters. We aimed to grasp the overview of compensated work-related injury among firefighters using the claimed data collected by the Korea Government Employee Pension Service (GEPS) from 2010 to July 2015, and use as preliminary data for establishing work-related injury prevention policies among firefighters.

\section{Methods}

\section{Study participants}

We requested the all claimed work-related injury data of Korean firefighters from 2010 to 2015 to the NFA. We analyzed 2154 approved firefighter cases from among 2457 claimed firefighter cases who submitted compensation applications for work-related injuries to the GEPS from January 2010 to July 2015. Only injury cases were included in this analysis.

\section{Variables}

We analyzed job activity, accident cause, injury type, the region of fire station and recuperation duration among 2154 approved cases. Among 2154 approved cases, we could get more information about age, sex and job duration in 1344 compensated cases through the text file for summary of accident. In the statistical data of the
NFA, the incidence of work-related injuries were analyzed by referring to the number of firefighters and the frequency of dispatch [9-13].

Compensated cases were classified based on four categories: sex (male, female), age (20-29, 30-39, 4049, 50-59 years, 60 years and over), region of fire station (Seoul, Busan, Daegu, Incheon, Gwangju, Daejeon, Ulsan, Gyeonggi, Gangwon, Chungbuk, Chungnam, Jeonbuk, Jeonnam, Gyeongbuk, Gyeongnam, and Jeju), and job duration $(0-5,5-10,10-20,20-30,30$ years and over).

The causes of accident were classified as falling from a height, slips, falling beneath, coming into contact with an object, being struck with an object, being trapped, involvement in a structural collapse, movement imbalance, hazardous and dangerous material exposure, fire, violence, traffic accident, and others based on the Industrial Accident Cause Statistics of the Ministry of Employment and Labor [13]. The incidence of work-related injuries is expressed in a number of injuries per 1000 firefighters. The job activities were classified as fire suppression, emergency medical services (EMS), rescue, training, respond/return, commuting, office work or facility repair, outside work service, athletic events, and others. The type of injuries was classified as sprains and bruises, fractures, ligament injury and dislocations, nerve injury, muscle injury, laceration or injury from a bite, burns, amputations, poisoning, hearing loss, visual impairment, frostbite, and others. Body parts of injuries were classified as head, neck, shoulder, arm, forearm and hand, trunk, upper and lower back, upper leg and knee, lower leg and knee, and others.

\section{Statistical analysis}

The descriptive analyses were performed for sex, age, job duration, region of fire station, job activity, accident cause, and injury type using the SPSS version 21.0 software program.

\section{Results}

Incidence of work-related injuries

The GEPS recognized 2154 (87.7\%) approved work-related injuries among 2457 claimed cases. The proportion of compensated work-related injuries per year was as follow: $87.8 \%$ in $2010,87.8 \%$ in $2011,85.0 \%$ in $2012,87.6 \%$ in 2013, $87.9 \%$ in 2014 and $90.8 \%$ from January to July 2015 (Fig. 1).

The incidence of work-related injuries per 1000 firefighters was 9.8, from 8.7 in 2013 to 11.0 in 2011. Based on the analysis of the region of fire station, the Gyeonggi Province was the largest proportion of compensated cases (415, 19.3\%), followed by $382(17.7 \%)$ in Seoul, and 161 (7.5\%) in Daegu. The incidence of work-related injuries per 1000 firefighters was the highest in Daegu area (14.4), followed by Jeonbuk (13.7), and Gangwon Province (12.5). 


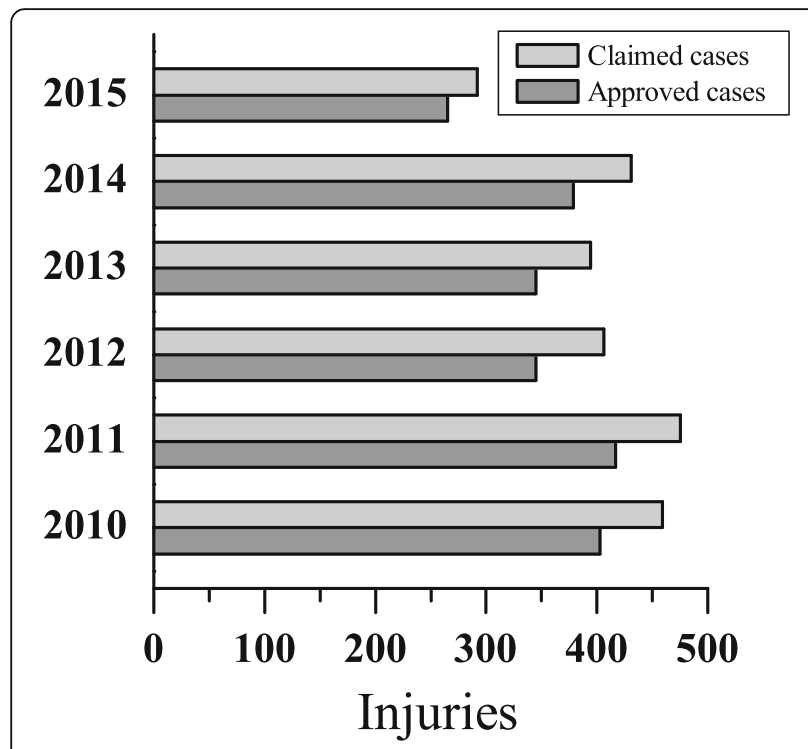

Fig. 1 Number of claimed or approved work-related injuries by year. Gray bars mean total number of claimed cases, while dark gray is the total number of approved cases

The lowest in Gwangju (4.0), followed by Gyeongbuk (4.4), and Jeonnam (7.1) (Table 1).

From 2010 to 2014, the monthly incidence of work-related injuries was high during the period from April to June; 186 in April (9.8\%), 197 in May (10.4\%), and 173 in June (9.2\%). The number of work-related injuries per 1000 dispatches was 8.9. February was the lowest at 6.0, and August was the highest at 11.5. No increase in incidence with increasing dispatch was observed (Table 2).

\section{Burden of work-related compensated injuries (recuperation duration and compensation cost)}

The average recuperation duration during the study period was 96.4 days. The recuperation duration was the longest at 115.2 days in 2013 (Standard deviation, SD: 104.0), and the shortest was 67.7 days in 2011 (SD: 54.8). The per-claim average compensation cost of injury to firefighters was 358,780 won. In 2013 , it was the highest at 520,926 won (SD: 1,028,345), the lowest at 155,049 won in 2011 (SD: 648,347) (Fig. 2).

\section{Characteristics of compensated work-related injuries}

We analyzed 2154 approved work-related injuries for job activities, causes of accident and type of injuries (Table 3).

The most common job activity at the time of accident was fire suppression $(n=387,18.0 \%)$, followed by rescue activities $(n=377,17.5 \%)$, training $(n=230,10.7 \%)$, respond/return ( $n=200,9.3 \%)$, and commuting ( $n=199$, 9.2\%) (Fig. 3). In terms of accident cause, movement imbalance was the most common cause $(n=652,30.3 \%)$, followed by falls $(n=408,18.9 \%)$, traffic accidents $(n=$ $289,13.4 \%)$, falling from a height $(n=179,8.3 \%)$, and coming into contact with an object $(n=176,8.2 \%)$ (Fig. 4).

Table 1 The incidence of approved work-related injuries per 1000 firefighters by the region and year (2010 to 2014)

\begin{tabular}{|c|c|c|c|c|c|c|c|c|c|c|c|c|c|c|c|c|c|c|c|}
\hline \multicolumn{2}{|c|}{ Variables } & \multicolumn{3}{|l|}{2010} & \multicolumn{3}{|l|}{2011} & \multicolumn{3}{|l|}{2012} & \multicolumn{3}{|l|}{2013} & \multicolumn{3}{|l|}{2014} & \multicolumn{3}{|l|}{ Total } \\
\hline & & $\overline{N^{a}}$ & $n^{\mathrm{b}}$ & $\% 0^{c}$ & $\overline{N^{a}}$ & $n^{b}$ & $\% 0^{c}$ & $\overline{N^{a}}$ & $n^{\mathrm{b}}$ & $\% 0^{c}$ & $\overline{N^{a}}$ & $n^{\mathrm{b}}$ & $\% 0^{c}$ & $\overline{N^{a}}$ & $n^{\mathrm{b}}$ & $\% 0^{c}$ & $\overline{N^{a}}$ & $n^{\mathrm{b}}$ & $\% c^{c}$ \\
\hline \multirow[t]{16}{*}{ Region } & Seoul & 5800 & 67 & 11.6 & 6051 & 90 & 14.9 & 6359 & 55 & 8.7 & 6501 & 51 & 7.8 & 6461 & 70 & 10.8 & 30,839 & 333 & 10.7 \\
\hline & Busan & 2546 & 34 & 13.4 & 2546 & 28 & 11.0 & 2559 & 26 & 10.2 & 2594 & 20 & 7.7 & 2635 & 20 & 7.6 & 12,752 & 128 & 9.9 \\
\hline & Daegu & 1878 & 34 & 18.1 & 1959 & 24 & 12.3 & 1959 & 18 & 9.2 & 1985 & 31 & 15.6 & 1975 & 34 & 17.2 & 9615 & 141 & 14.5 \\
\hline & Incheon & 2222 & 16 & 7.2 & 2237 & 18 & 8.1 & 2246 & 7 & 3.1 & 2255 & 27 & 12.0 & 2236 & 27 & 12.1 & 11,101 & 95 & 8.5 \\
\hline & Gwangju & 1092 & 6 & 5.5 & 1092 & 6 & 5.5 & 1092 & 5 & 4.6 & 1115 & 3 & 2.7 & 1108 & 2 & 1.8 & 5477 & 22 & 4.0 \\
\hline & Daejeon & 1129 & 11 & 9.7 & 1136 & 17 & 15.0 & 1139 & 13 & 11.4 & 1158 & 12 & 10.4 & 1157 & 10 & 8.6 & 5656 & 63 & 11.0 \\
\hline & Ulsan & 717 & 12 & 16.7 & 777 & 11 & 14.2 & 835 & 8 & 9.6 & 835 & 3 & 3.6 & 828 & 10 & 12.1 & 3948 & 44 & 11.0 \\
\hline & Gyeonggi & 5538 & 81 & 14.6 & 5957 & 77 & 13.0 & 6176 & 62 & 10.0 & 6176 & 70 & 11.3 & 6418 & 67 & 10.4 & 29,908 & 357 & 11.8 \\
\hline & Gangwon & 2277 & 28 & 12.9 & 2203 & 30 & 13.6 & 2253 & 22 & 9.8 & 2290 & 29 & 12.7 & 2291 & 31 & 13.5 & 11,074 & 140 & 12.5 \\
\hline & Chungbuk & 1378 & 16 & 11.6 & 1382 & 16 & 11.6 & 1456 & 13 & 8.9 & 1479 & 13 & 8.8 & 1462 & 6 & 4.1 & 7093 & 64 & 8.9 \\
\hline & Chungnam & 2033 & 21 & 10.3 & 2059 & 17 & 8.3 & 1986 & 20 & 10.1 & 2270 & 18 & 7.9 & 2270 & 10 & 4.4 & 10,532 & 86 & 8.1 \\
\hline & Jeonbuk & 1970 & 21 & 10.7 & 1970 & 23 & 11.7 & 1970 & 32 & 16.2 & 1970 & 27 & 13.7 & 1927 & 31 & 16.1 & 9673 & 134 & 13.7 \\
\hline & Jeonnam & 2058 & 14 & 6.8 & 2062 & 17 & 8.2 & 2066 & 12 & 5.8 & 2066 & 10 & 4.8 & 2022 & 20 & 9.9 & 10,201 & 73 & 7.1 \\
\hline & Gyeongbuk & 2570 & 13 & 5.1 & 2747 & 9 & 3.3 & 2934 & 13 & 4.4 & 3033 & 13 & 4.3 & 2976 & 14 & 4.7 & 14,198 & 62 & 4.3 \\
\hline & Gyeongnam & 2764 & 22 & 8.0 & 2764 & 27 & 9.8 & 2780 & 28 & 10.1 & 2823 & 10 & 3.5 & 2796 & 20 & 7.2 & 13,820 & 107 & 7.7 \\
\hline & Jeju & 594 & 7 & 11.8 & 627 & 7 & 11.2 & 647 & 11 & 17.0 & 647 & 7 & 10.8 & 647 & 7 & 10.8 & 3123 & 39 & 12.3 \\
\hline Total & & 36,711 & 403 & 11.0 & 37,826 & 417 & 11.0 & 38,557 & 345 & 8.9 & 39,519 & 344 & 8.7 & 40,406 & 379 & 9.4 & 191,131 & 1888 & 9.8 \\
\hline
\end{tabular}


Table 2 The incidence of approved work-related injuries per 1000 dispatches by the month

\begin{tabular}{|c|c|c|c|c|c|c|c|c|c|c|c|c|c|}
\hline Variable & Jan. & Feb. & Mar. & Apr. & May. & Jun. & Jul. & Aug. & Sep. & Oct. & Nov. & Dec. & Total \\
\hline Compensated cases & 158 & 122 & 163 & 186 & 197 & 173 & 158 & 161 & 136 & 158 & 146 & 131 & 1889 \\
\hline Total Dispatches & 21,774 & 20,299 & 22,186 & 20,085 & 18,166 & 16,053 & 14,024 & 14,007 & 13,605 & 15,821 & 16,483 & 19,550 & 212,053 \\
\hline work-related injuries per 1000 Dispatches & 7.3 & 6.0 & 7.3 & 9.3 & 10.8 & 10.8 & 11.3 & 11.5 & 10.0 & 10.0 & 8.9 & 6.7 & 8.9 \\
\hline
\end{tabular}

In terms of injury type, sprains and bruises were the most common $(n=586,27.2 \%)$, followed by fractures $(n$ $=501,23.3 \%)$, ligament injuries and dislocations $(n=$ $421,19.5 \%)$, nerve injuries ( $n=177,8.2 \%)$, and sharps or bite injuries $(n=115,5.3 \%)$.

The upper and lower back were the most commonly injured sites $(n=544,25.3 \%)$, followed by the upper leg and knee $(n=368,17.1 \%)$, the lower leg and foot $(n=267,12.4 \%)$, the head $(n=262,12.2 \%)$, and the forearm and hand ( $n=219,10.2 \%)$.

\section{The characteristics of identified firefighters}

Among 2154 approved work-related injuries, only 1344 firefighters were identified such variables as sex, age and job duration through the text file for accident summary (Table 4).

$1264(94.0 \%)$ were male and $80(6.0 \%)$ were female. The average age of firefighters was 47.7. The most common age group was $40-49$ (46.4\%), followed by $30-39$ (35.5\%). Job duration was average 14.2 years. $10-20$ years were the largest with 650 (48.4\%), followed by $5-10$ years with 290 (21.6\%). A further analysis of the 10-20 years' job duration firefighter group, which accounted for a large proportion, did not show any difference from the other groups.

\section{Discussion}

The significance of this study is the analysis of the incidence, regional differences, cause of accident, and job activity through compensated work-related injury data of NFA for about 5 years in all firefighters in Korea.

The incidence of compensated work-related injuries per 1000 firefighters was just 9.8 persons. However, there is a large difference between this finding and the results of a previous survey of work-related injuries of Korean firefighters that reported 116 cases per 1000 firefighters within the preceding 12 months [1]. This difference is likely due to a number of firefighters not claiming compensation for work-related injury compensation even when they had experienced a work-related injury. 33 Korean firefighters died on duty from 2010 to 2014 . The rate of on-duty deaths per 100,000 firefighters in Korea is 83.2, compared to 35.9 in US firefighters [3]. This suggests that firefighters in Korea are exposed to more dangerous work environments. However, the accident rate is the opposite, the accident rate in the US in 2013 was $15.1 \%$, while the rate of injury in Korea was $0.7 \%$ in the same year. That means that a large number of firefighters compensated injury does not apply for non-fatal work-related injury [3]. The most common reason for not reporting work-related injuries was because of mild disease [14]. Furthermore, due to concerns

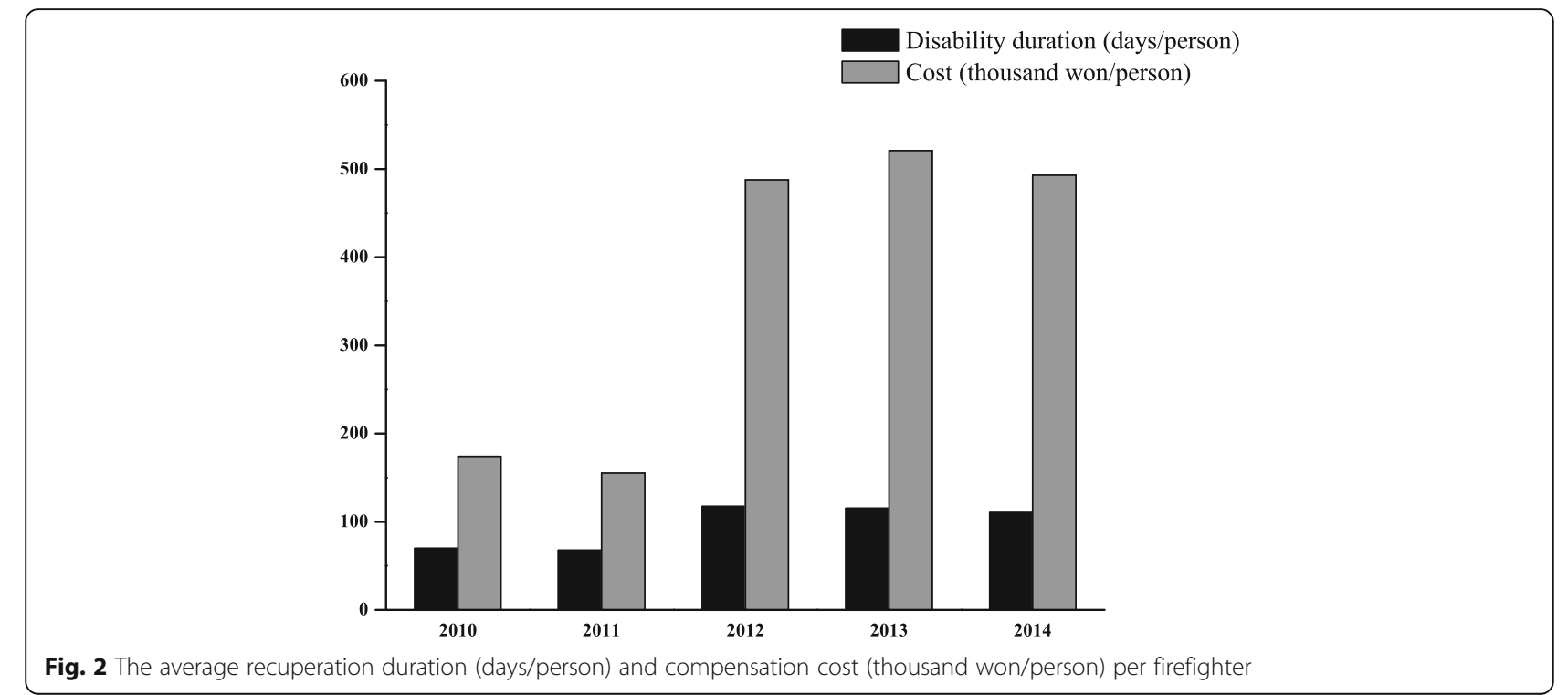


Table 3 Recuperation duration and amount of payment according to type of injuries and injured body sites

\begin{tabular}{|c|c|c|c|c|c|c|c|c|}
\hline \multirow[t]{2}{*}{ Variable } & \multirow[b]{2}{*}{$N$} & \multirow[b]{2}{*}{$\%$} & \multicolumn{3}{|c|}{ Recuperation duration (days) } & \multicolumn{3}{|c|}{ Compensation (thousand won) } \\
\hline & & & Mean & Median & Max & Mean & Median & Max \\
\hline All & 2154 & 100 & 96.4 & 60 & 1183 & 358.8 & 19.3 & $14,889.8$ \\
\hline Sprains and bruises & 586 & 27.2 & 52.9 & 60 & 228 & 88.0 & 0 & 2386.9 \\
\hline Fractures & 501 & 23.3 & 110.0 & 90 & 730 & 397.6 & 44.9 & $11,416.0$ \\
\hline Ligament injury and dislocations & 421 & 19.5 & 101.3 & 69 & 1183 & 527.8 & 52.9 & 6429.9 \\
\hline Nerve injury & 177 & 8.2 & 90.9 & 60 & 816 & 544.5 & 90.4 & 6407.1 \\
\hline Laceration or injury from bite & 115 & 5.3 & 68.6 & 60 & 236 & 106.9 & 9.7 & 1733.9 \\
\hline Muscle injury & 99 & 4.6 & 82.7 & 60 & 366 & 294.3 & 16.6 & 3096.0 \\
\hline Burns & 94 & 4.4 & 89.3 & 60 & 383 & 626.0 & 67.5 & $14,889.8$ \\
\hline Amputations & 12 & 0.6 & 86.2 & 61 & 180 & 186.0 & 0 & 2094.2 \\
\hline Poisoning & 8 & 0.4 & 64.9 & 60 & 99 & 110.0 & 23.5 & 450.7 \\
\hline Hearing loss & 8 & 0.4 & 112.6 & 60 & 464 & 121.7 & 0 & 551.9 \\
\hline Visual impairment & 4 & 0.2 & 46.8 & 60 & 60 & 4.7 & 0 & 18.7 \\
\hline Frostbite & 1 & 0.0 & 60.0 & 60 & 60 & 0 & 0 & 0 \\
\hline Others & 128 & 5.9 & 278.8 & 92 & 883 & 773.8 & 14.9 & $11,343.6$ \\
\hline Upper and lower back & 544 & 25.3 & 73.7 & 60 & 816 & 296.2 & 17.9 & 7965.7 \\
\hline Upper leg and knee & 368 & 17.1 & 94.0 & 63 & 1183 & 477.0 & 30.1 & 6429.9 \\
\hline Lower leg and foot & 267 & 12.4 & 98.6 & 78 & 726 & 416.7 & 64.2 & $11,416.0$ \\
\hline Head & 262 & 12.2 & 103.0 & 60 & 883 & 265.5 & 0 & $14,889.8$ \\
\hline Forearm and hand & 219 & 10.2 & 89.7 & 60 & 366 & 223.6 & 30.8 & 4139.6 \\
\hline Shoulder & 128 & 5.9 & 82.9 & 60 & 309 & 436.2 & 10.1 & 3702.2 \\
\hline Trunk & 107 & 5.0 & 100.1 & 60 & 383 & 389.0 & 0 & 4980.0 \\
\hline Neck & 79 & 3.7 & 65.9 & 60 & 263 & 79.5 & 0 & 1283.2 \\
\hline Arm & 68 & 3.2 & 99.1 & 72 & 320 & 367.5 & 36.3 & 8105.7 \\
\hline Others & 112 & 5.2 & 239.3 & 90 & 730 & 693.0 & 13.8 & $11,343.6$ \\
\hline
\end{tabular}

that reporting work-related injuries would be a burden to their colleagues or to the fire service, a failure to recognize a work-related injury or ignorance of the application procedure may have resulted in late reporting of work-related injuries, and neglect and aggravation of the injury [15]. Consequently, the work-related injury may have a long duration, and injury sequelae may require treatment for several days to several years, even after being treated as a compensated work-related injury. Therefore, systematic injury report systems and treatment systems for managing work-related injuries are needed. This provides additional insight into mild or severe but not reported injuries. There is a difference in incidence by region. To find out the cause, it is necessary to study the difference in the number of firefighting activities, preventive measures, and accessibility of compensated injuries. Preventive measures can be established through these studies.

Analysis of recuperation duration and compensation cost shows that these are constantly increasing. Although the increase in medical expenses every year can be judged by an increase in medical prices, a sharp increase from 2010 to 2015 can be interpreted as occupational injuries becoming more severe and becoming chronic. It is reported that during the recuperation duration, many firefighters fail to fully recover, paying their personal costs and receiving additional treatment [16]. Therefore, it is necessary to prevent deterioration of injury through early detection and early treatment, and to minimize the loss of firepower through quick recovery for them to return to work.

The most common job activity that caused the accident was fire suppression $(n=387,18.0 \%)$, followed by EMS $(n=377,17.5 \%)$, and training $(n=230,10.7 \%)$. There was a high probability that firefighters may be injured during fire dispatch since, according to the statistics data released by the NFA, fire dispatches, rescue activity, and EMS accounted for $1.6 \%, 18.6 \%$ and $79.8 \%$ of all the dispatches from 2010 to 2014, respectively [9-13]. 927 compensated cases (43.0\%) occurred in direct firefighting activities such as fire suppression, EMS, rescue, and 391 compensated cases (18.2\%) occurred in 

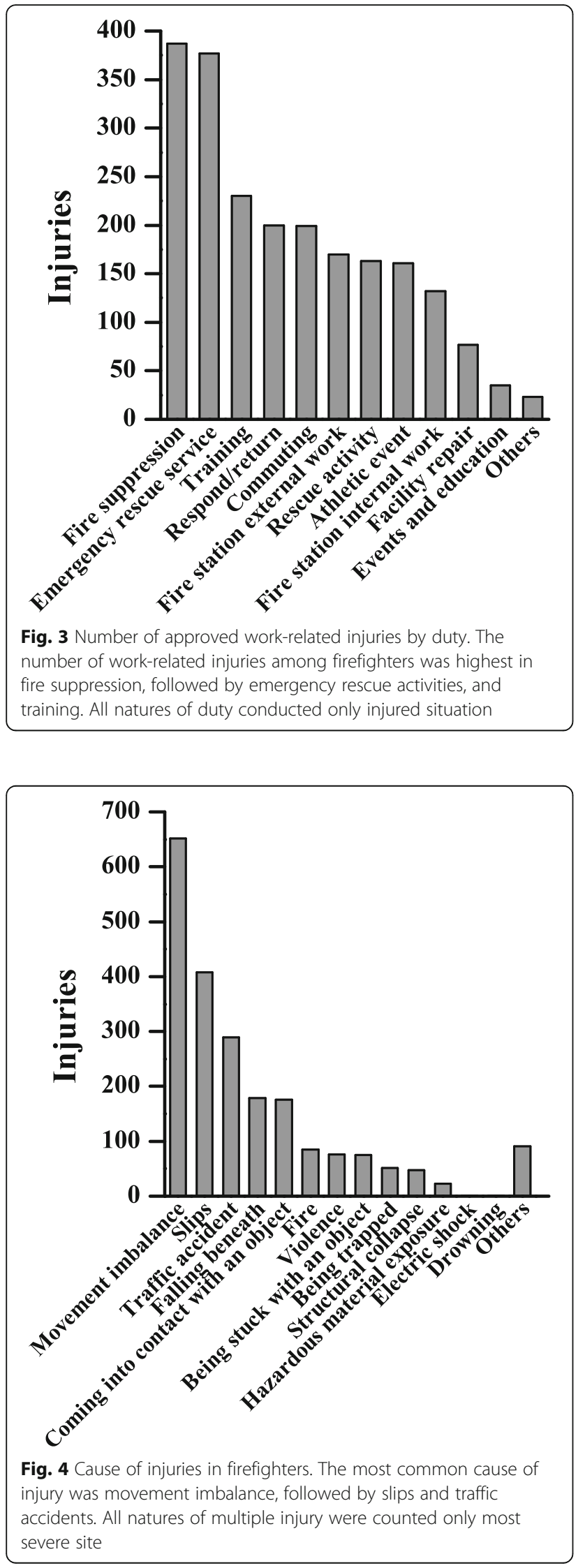

Table 4 The characteristics of a part of study subjects

\begin{tabular}{lll}
\hline Variable & $n$ & $\%$ \\
\hline Sex & 1264 & 94.0 \\
Male & 80 & 6.0 \\
Female & \\
Age (years) & \\
$20-29$ & 41 & 3.1 \\
$30-39$ & 477 & 35.5 \\
$40-49$ & 623 & 46.4 \\
$50-59$ & 200 & 14.9 \\
$\geq 60$ & 3 & 0.2 \\
Job duration (years) & & \\
$<5$ & 109 & 8.1 \\
$5-10$ & 290 & 21.6 \\
$10-20$ & 650 & 48.4 \\
$20-30$ & 258 & 19.2 \\
$\geq 30$ & 37 & 2.8 \\
\hline
\end{tabular}

training and athletic events. This indicates that current training has become an important cause of work-related injuries among firefighters, and in conflict with its original purpose of preventing injuries and enhancing job performance. And effective training methods to prevent injuries occurring during training or athletic events [17-19].

Also, 199 cases $(9.2 \%)$ of injuries were caused by traffic accidents. Further studies are needed to determine whether the occurrence of a traffic accident is a work-related fatigue due to shift work. Previous studies have also shown that decreased concentration was associated with increased occupational accidents or traffic accidents [20-23]. Therefore, it is necessary to study the fatigue caused by the shift work of the firefighters and their effects.

We reviewed the compensated work-related injuries applications received by the NFA and analyzed the causes of the injury in detail. The most common injuries pertained to musculoskeletal injuries of the lower back or lower legs, caused by a movement or a fall. Therefore, preventive measures against frequent injuries should be given priority. Programs should be developed to improve the strength and flexibility or frequent injured sites in firefighter training [17-19]. In addition, financial and medical support should be need, until an individual fully recovers from a work-related injury [6, 24, 25]. Further studies should prioritize injuries that occur frequently but which are not yet addressed through preventative or management measures.

Among 2154 approved cases, we could analyze more variables for the sex, age, and job duration of 1344 compensated cases $(62.4 \%)$. However, there are insufficient data on sex, age, and job duration for all compensated cases. As a result, since there is no data on the number 
of firefighters per job duration, duty, sex, and age, there is a limitation of research that fails to calculate the incidence rate of firefighters by job duration, duty, sex, and age. We could not be concluded that incidence of injury is high or low depending on these characteristics due to missing components of data. 10-20 years' firefighter, which can be judged to high proficiency, accounts for $48.4 \%$ of all in all injuries, suggests that preventive education for the skilled firefighter is needed continuously.

\section{Conclusion}

In summary, as a result of the study, we could obtain the information necessary to establish preventive measures such as cause of accident and region with high accident rates. However, the number of applications for compensated injuries was very small compared to the frequency of injuries found in previous studies. This suggested that many firefighter injuries can become chronic due to lack of appropriate treatment, so it is necessary to introduce an injury monitoring system and improve the accessibility of compensated injuries. In addition, the results of this study can be used to analyze the changing trend of work-related injuries among firefighters and to compare occupational accidents with other occupations in the future; they can also be used as baseline data for establishing work-related injury prevention policies for firefighters.

\section{Abbreviations}

EMS: Emergency medical services; GEPS: Government Employees Pension Service; NFA: National Fire Agency

\section{Acknowledgements}

This research was supported by the Field-oriented Support of Fire Fighting Technology Research and Development Program funded by National Fire Agency ("MPSS-Fire Fighting Safety-2017-87").

\section{Funding}

This study was funded by the National Fire Agency ("MPSS-Fire Fighting Safety-2017-87").

\section{Availability of data and materials}

Please contact author for data requests.

\section{Authors' contributions}

HDK: The first author of this article. He designed the study, interpreted the data, and drafted the manuscript. YSA: The corresponding author of this article. She suggested the study design, interpreted the data, and revised the manuscript. KSJ: She consulted the study method and revised the manuscript. YSA and DHK: They reviewed and revised the submitted manuscript. All authors have approved the final version of the manuscript.

\section{Ethics approval and consent to participate}

This study was conducted with the approval of the institutional review board of Wonju College of Medicine (ID: CR318031).

\section{Consent for publication}

Not applicable.

\section{Competing interest}

The authors declare that they have no competing interests.

\section{Publisher's Note}

Springer Nature remains neutral with regard to jurisdictional claims in published maps and institutional affiliations.

\section{Author details}

${ }^{1}$ Department of Preventive Medicine and Institute of Occupational and Environmental Medicine, Wonju College of Medicine, Yonsei University, 20 Ilsan-ro, Wonju, Gangwon-do 26426, Republic of Korea. ${ }^{2}$ Department of Occupational and Environmental Medicine, Inha University Hospital, 27 Inhang-ro, Jung-gu, Incheon 22332, Republic of Korea. ${ }^{3}$ Department of Occupational and Environmental Medicine, Soonchunhyang University Cheonan Hospital, 31 Suncheonhyang 6-gil, Dongnam-gu, Cheonan-si, Chungcheongnam-do 31151, Republic of Korea. ${ }^{4}$ Department of Occupational and Environmental Medicine, Dongguk University Ilsan Hospital, 27 Dongguk-ro, Ilsandong-gu, Goyang 10326, Republic of Korea. ${ }^{5}$ Department of Occupational and Environmental Medicine, Hallym University Sacred Heart Hospital, 22 Gwanpyeong-ro 170beon-gil, Dongan-gu, Anyang-si, Gyeonggi-do 14068, Republic of Korea.

Received: 6 March 2018 Accepted: 29 August 2018

Published online: 03 September 2018

\section{References}

1. Yoon J-H, Kim Y-K, Kim KS, Ahn Y-S. Characteristics of workplace injuries among nineteen thousand Korean firefighters. J Korean Med Sci. 2016; 31(10):1546-52.

2. Houser A, Jackson BA, Bartis JT, Peterson D: Emergency responder injuries and fatalities: RAND Corporation; 2004.

3. Kim TB, Byun HJ, Kang TS. $4 \mathrm{M}$ analysis of the factors affecting firefighters' on-site safety. Journal of Korean Society of Occupational and Environmental Hygiene. 2017;27(3):231-7.

4. Kim DH, An YS, Kim HD, Jeong KS, Ahn Y-S, Kim K-H, Kim Y, Song H-S, Lee C-G, Kwon Y-J. Comparison of facet joint degeneration in firefighters and hospital office workers. Annals of occupational and environmental medicine. 2017:29(1):24.

5. Kim MG, Kim K-S, Ryoo J-H, Yoo S-W. Relationship between occupational stress and work-related musculoskeletal disorders in Korean male firefighters. Annals of occupational and environmental medicine. 2013;25(1):9.

6. Frost D, Beach T, Crosby I, McGill S. Firefighter injuries are not just a fireground problem. Work. 2015;52(4):835-42.

7. Ide C. Hearing loss, accidents, near misses and job losses in firefighters. Occup Med (Lond). 2007:57(3):203-9.

8. Kang TS HO, Kim KS, Yoon CS.: Hearing among male firefighters: a comparison with hearing data from screened and unscreened male population. . Journal of Exposure Science and Environmental Epidemiology 2015, 01(25(1)):106-112.

9. Agency NEM: Statistics and Data for Fire Disaster Prevention Activities in 2010. In. Edited by Agency NEM, vol. 1. National Emergency Management Agency: National Emergency Management Agency; 2011.

10. Agency NEM: Statistics and data for fire disaster prevention activities in 2011. In. Edited by agency NEM, vol. 1: National Emergency Management Agency; 2012.

11. Agency NEM: Statistics and data for fire disaster in 2012. In. Edited by agency NEM, vol. 1: National Emergency Management Agency; 2013.

12. Agency NEM: Statistics and data for fire disaster in 2013. In. Edited by agency NEM, vol. 1: National Emergency Management Agency; 2014.

13. Labor MoEa: 2014 industrial accident cause statistics report. In. Ministry of Employment and Labor; 2015.

14. Hyun SH, Cha JM, Lee YJ, Song YS, Kim HS, Ahn YS. An analysis on current conditions of occupational casualties of firefighters. Proceedings of the Korea Institute of Fire Science and Eng Conf. 2009:383-91.

15. Ahn YS, Hyun S, Jeong K, Kim K, Choi K, Chae J. The analysis of risk factors related health and safety at disasters and development of special medical health examination system for firefighters. Seoul: Korea National Emergency Management Agency; 2011.

16. Ahn YS. The problem of the compensated injury system of public officials and the lumbar spine of the firefighter compensated injury recognition standards. In: 2015: the Korean society of occupational and environment; 2015. p. 46-7. 
17. Beach TA, Frost DM, McGill SM, Callaghan JP. Physical fitness improvements and occupational low-back loading-an exercise intervention study with firefighters. Ergonomics. 2014;57(5):744-63.

18. Frost DM, Beach TA, Callaghan JP, McGill SM. Exercise-based performance enhancement and injury prevention for firefighters: contrasting the fitnessand movement-related adaptations to two training methodologies. The Journal of Strength \& Conditioning Research. 2015;29(9):2441-59.

19. Pawlak R, Clasey JL, Palmer T, Symons TB, Abel MG. The effect of a novel tactical training program on physical fitness and occupational performance in firefighters. The Journal of Strength \& Conditioning Research. 2015;29(3): 578-88.

20. Sonmez S, Ursavas A, Uzaslan E, Ediger D, Karadag M, Gozu O, Ege E. Sleep disorders and occupational accident in shift work nurses. Chest. 2014; 146(4:947A

21. Gerber M, Hartmann T, Brand S, Holsboer-Trachsler E, Pühse U. The relationship between shift work, perceived stress, sleep and health in Swiss police officers. J Crim Just. 2010;38(6):1167-75.

22. Özdemir PG, Selvi Y, Özkol H, Aydın A, Tülüce Y, Boysan M, Beşiroğlu L. The influence of shift work on cognitive functions and oxidative stress. Psychiatry Res. 2013;210(3):1219-25.

23. Dembe AE, Erickson JB, Delbos RG, Banks SM. The impact of overtime and long work hours on occupational injuries and illnesses: new evidence from the United States. Occup Environ Med. 2005;62(9):588-97.

24. Buckle P. Ergonomics and musculoskeletal disorders: overview. Occup Med. 2005;55(3):164-7.

25. Seabury SA, McLaren CF. The Frequency, Severity, and Economic Consequences of Musculoskeletal Injuries to Firefighters in California. Rand health quarterly. 2012;2(3)

Ready to submit your research? Choose BMC and benefit from:

- fast, convenient online submission

- thorough peer review by experienced researchers in your field

- rapid publication on acceptance

- support for research data, including large and complex data types

- gold Open Access which fosters wider collaboration and increased citations

- maximum visibility for your research: over $100 \mathrm{M}$ website views per year

At $\mathrm{BMC}$, research is always in progress.

Learn more biomedcentral.com/submissions 